\title{
Comparative Study on Seismic Behaviour of Composite and RCC plan Irregular Structures
}

\author{
Mohammed Akif Uddin \\ PG Scholar, \\ Dept. of Civil Engineering \\ Deccan College of Engineering and Technology, \\ Hyderabad, India
}

\author{
M. A. Azeem \\ Assistant Professor, \\ Dept. of Civil Engineering \\ Deccan College of Engineering and Technology, \\ Hyderabad, India
}

\begin{abstract}
This paper investigates comparison of a composite structure with concrete filled steel tubular columns, a composite structure with concrete encased I section columns and a RCC structure. All the models considered are $\mathrm{G}+15$ storey and are irregular in plan and the irregularity condition as per IS 1893-2002 is satisfied resulting in $T$ shape and Plus Shape models. It was observed after performing response spectrum analysis on the models that the stiffness is less in composite structures when compared to RCC structures. The displacements and drifts are less in RCC structures owing to larger value of stiffness but are within the permissible limits. The base shear and base moments are found to be less in composite structures due to the fact that the dead weight of composite structures is less compared to RCC structures. There is no significant difference in the response parameters of the two composite structures.
\end{abstract}

Keywords-Concrete Encased I Section Column, Concrete Filled Steel Tabular column, RCC, Response Spectrum Analysis

\section{INTRODUCTION}

As the population in the world is increasing at a faster rate the need for buildings are also going hand in hand. As some of the countries are short in terms of area, the need for taller buildings becomes essential in the society. Composite construction is formed when two heterogeneous materials are bonded together as a single element. The composite structures such as steel encased with concrete are economical, time and cost efficient in major civil structures such as bridges and high-rise building. In past, for the design of buildings, the choice was between a concrete structure or masonry structure. With the failure of these structures due to earthquakes forced the structural engineers to find an alternative method of construction. Many structural engineers in India are not welcoming the use of steel-concrete composite buildings because of its unfamiliarity, lack of awareness and its analysis and design seems to be little complex. From the literature available in this area it can be said if properly configured, then composite steel-concrete system will provide extremely economical structural systems with speedy construction, high durability and high seismic performance characteristics.

\section{LITERATURE REVIEW}

Vamshi Krishna, S.V. Surendhar. [1] presented a paper showing the comparison of seismic analysis of RCC and composite 18 storey building. The results show that some parameters such as time periods and story displacements were higher in composite and story forces bending moment and shear forces were less in composite structures. Sachin S [2] presented a paper on the seismic behaviour of 15 story irregular building through dynamic analysis as per IS 1893:2002 for seismic zone 4 and soil type medium. The results were compared for various parameters like time periods, frequency, story drifts and story displacement. CFST columns where compared with the CEC columns. Sohail Shaikh [3] conducted a study on behavior of Concrete encased columns in irregular buildings under seismic conditions. A detailed analysis of multi-story $\mathrm{G}+20$ building having various irregularities with concrete encased columns is been carried out against RCC columns in mass and stiffness irregularity. Base shear was found to be reduced in concrete encased columns in both the irregularities. The time periods and the displacements were found to be higher in composite structure when compared with the RCC structure. He concluded that concrete encased columns are suitable for stiffness irregularity building due to its high stiffness property which enables the structure to resist. Vishwanatha S N [4] presented a paper on seismic analysis of multi-story RCC and composite building subjected to vertical irregularity. The study is carried out on the comparison of RCC with composite structure for G+16 building situated in seismic zone 5. The models consist of Rectangular, mass irregularity, stiffness irregularity and geometrical irregularity and the composite beams are provided without shear connectors. The result parameters which are compared were base shear, story displacement and story drifts. Muhammed Sabith K [5] presented a paper on behaviour of seismic analysis of irregular composite structures with shear connectors. The study is carried out on plan irregular structure of medium rise building of 10 storey building. Modelling and analysis done to estimate the behaviour of shear connector and is compared with the RCC structure. It was found that story displacement is higher in composite structure. The composite structure has reduced stiffness to make the structure flexible. Story drifts are large in composite structure than RCC. Axial forces are reduced by nearly 50 percent margin in composite structures. Rajendra R. Bhoir, Vinay Kamble [6] presented a paper of comparison of Composite and RCC buildings. Two $\mathrm{G}+15$ residential buildings of composite and RCC structure are analysed and designed using ETABS with different story heights of $3 \mathrm{~m}$ and $4 \mathrm{~m}$. It is found that the depth of beams in composite structure is less than RCC structure, which results to also reduce the sizes of columns in composite structure. The design of smaller sections for same loading in beams and columns. For same structure, when the floor height is 
increased, it is found that, it doesn't make big changes to axial forces and bending moments.

This study aims to compare the response parameters like displacements, drifts, stiffness, shear, moments and axial forces of G+15 storey plan irregular composite structure with concrete encased columns, plan irregular composite structure with concrete filled columns and conventional RCC structure models located in seismic zone 5 .

\section{METHODOLOGY}

\section{A. Elements of Composite Construction}

A steel-concrete sectional composite beam is fabricated with the help of a steel beam sandwiched over a reinforced concrete slab is cast by using an element called shear connectors. Shear connectors improve the load carrying capacity of the element/member and overall rigidity in steel-concrete composite beam. The two primary functions of shear connectors are (a) at the interface of beam and slab, this transmits the shear acting along longitudinal, and (b) helps in avoiding the steel beam and concrete slab splitting at the interface/junction. The overall depth of the beam is decreased by the action between steel beam and concrete slab. A metal deck sheeting is provided on beam and with the help of shear connectors the deck sheeting and the beam are connected. Then the concreting is done over the deck sheeting. Figure 1 shows the composite deck slab.

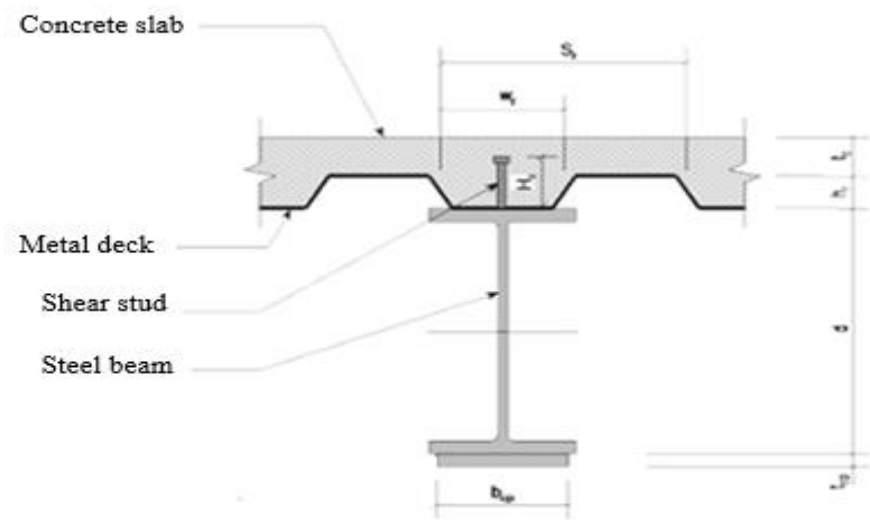

Fig. 1. Deck Slab

A column is considered as a compression member. Concrete encased I Section, Concrete Filled Steel Tubular(CFST) are used in this paper. These both are designed using AISC 36010 codebook. Figure 2 indicates a concrete encased column and figure 3 shows CFST.
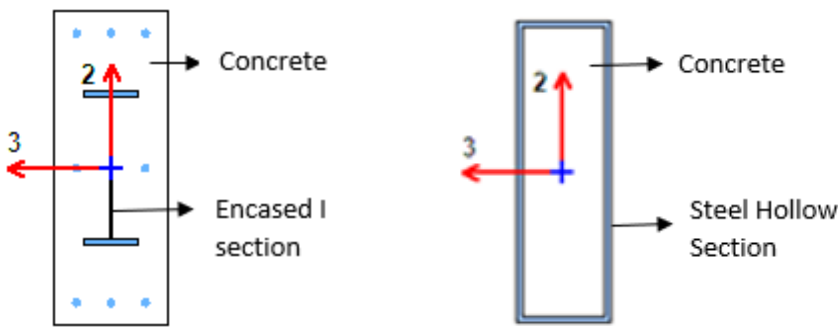

Fig. 2. Concrete Encased I-Section column

\section{B. Building Models used in the Study}

The study is carried out on for the behaviour of $\mathrm{G}+15$ storied building of $\mathrm{T}$ and Plus shaped models. The $\mathrm{T}$ shaped RCC model is labelled as RC-T15, composite structure with concrete encased I section columns as EN-T15 and composite structure with concrete filled steel tubular columns as FI-T15. Similarly, the Plus shaped models are labelled as RC-P15, EN-P15 and FI-P15 respectively. The geometric details of the building models are as shown in Table I. The loading details and the seismic parameters are shown in Tables II and III. The models were analysed in ETABS software. All the sections were designed as per codal requirements. The RCC model was designed using IS codes and the composite models were designed as per AISC-360 10 due to unavailability of Indian code for composite structures. Fig. 4 and 5 represent the plan and 3D view of T-shaped models. Fig. 6 and 7 represent the plan and 3D view of plus-shaped models.

TABLE I.

GEOMETRIC DETAILS OF THE BUILDING MODELS

\begin{tabular}{|c|c|c|}
\hline Item Description & \multicolumn{2}{|c|}{ Criteria } \\
\hline Shape of building & T Shape & Plus Shape \\
\hline Type of building & RCC, Composite & RCC, Composite \\
\hline Plan Dimension & $20 \mathrm{~m} \times 25 \mathrm{~m}$ & $20 \mathrm{~m} \times 35 \mathrm{~m}$ \\
\hline No. of Stories & 16 story & 16 story \\
\hline Total height of building & $48 \mathrm{~m}$ & $48 \mathrm{~m}$ \\
\hline Height of each Storey & $3 m$ & $3 \mathrm{~m}$ \\
\hline Sizes of composite columns & $300 \mathrm{~mm} \times 825 \mathrm{~mm}$ & $230 \mathrm{~mm} \times 600 \mathrm{~mm}$ \\
\hline Size of embedded I Section & ISMB400 & ISWB550 \\
\hline Thickness of Steel Tube & $15 \mathrm{~mm}$ & $15 \mathrm{~mm}$ \\
\hline Size of composite beams & ISLB 300 & ISLB 300 \\
\hline Composite slab thickness & $100 \mathrm{~mm}$ & $100 \mathrm{~mm}$ \\
\hline Metal deck sheeting & $100 \mathrm{~mm}$ & $100 \mathrm{~mm}$ \\
\hline Size of RCC Columns & \multicolumn{2}{|c|}{$300 \mathrm{~mm} \times 900 \mathrm{~mm}$} \\
\hline Size of RCC Beams & \multicolumn{2}{|c|}{$230 \mathrm{~mm} \times 600 \mathrm{~mm}$} \\
\hline Grade of concrete & \multicolumn{2}{|c|}{ M30 } \\
\hline Grade of steel & \multicolumn{2}{|c|}{ HYSD 500} \\
\hline
\end{tabular}

TABLE II. DETIALS OF THE LOADING APPLIED

\begin{tabular}{|c|c|}
\hline Item Description & Criteria \\
\hline Live Load & $3 \mathrm{KN} / \mathrm{m}^{2}$ \\
\hline Floor Finish & $2 \mathrm{KN} / \mathrm{m}^{2}$ \\
\hline Wall Load & $6 \mathrm{KN} / \mathrm{m}$ \\
\hline
\end{tabular}

TABLE III. SEISMIC LOAD PARAMETERS

\begin{tabular}{|l|c|}
\hline \multicolumn{1}{|c|}{ Item Description } & Criteria \\
\hline Seismic Zone considered & Zone 5 \\
\hline Zone Factor & 0.36 \\
\hline Importance Factor & 1 \\
\hline Rock and Soil type factor & 2 \\
\hline Response Reduction factor & 5 \\
\hline
\end{tabular}




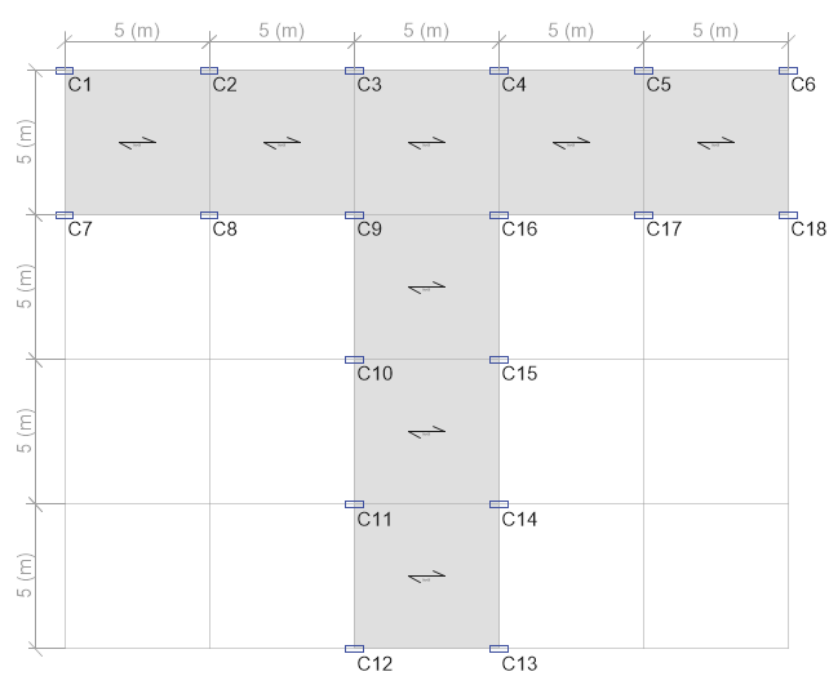

Fig. 4. Plan view of T-shaped models

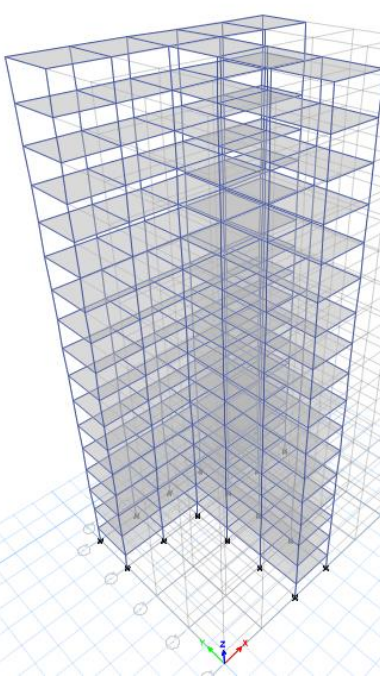

Fig. 5. 3D view of T-shaped models

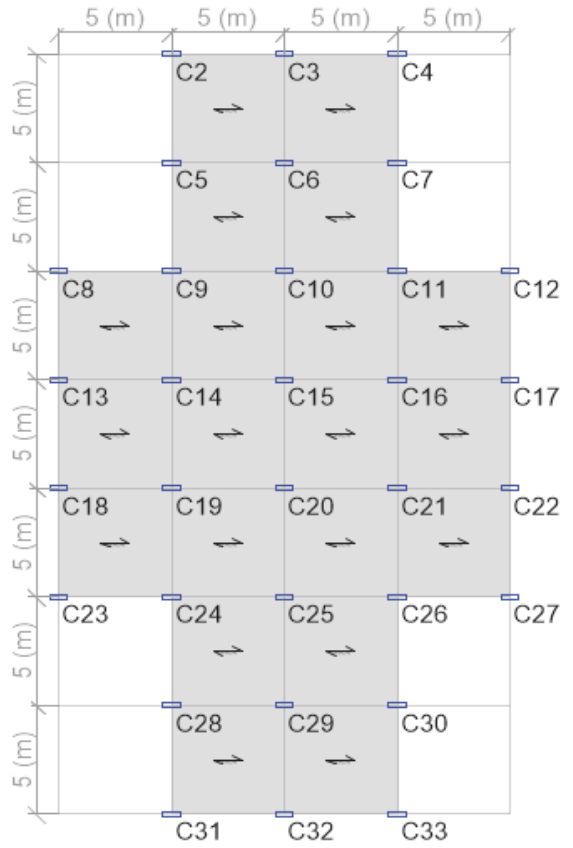

Fig. 6. Plan view of Plus-shaped models

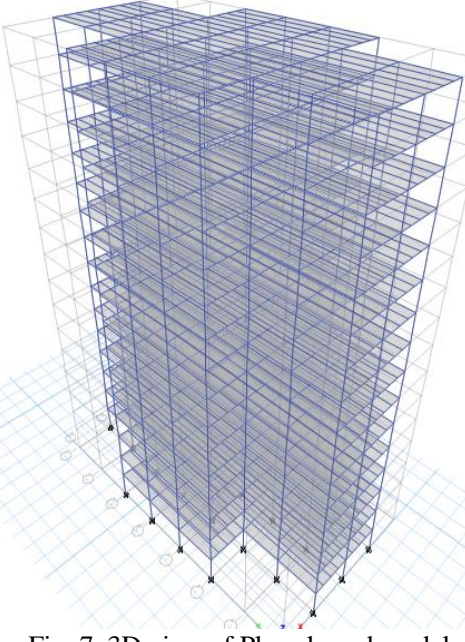

Fig. 7. 3D view of Plus-shaped models

IV. RESULTS AND DISCUSSION

\section{A. Time Periods}

TABLE IV. TIME PERIODS OF T-SHAPED MODELS

\begin{tabular}{|c|c|c|c|}
\hline Modes & RC-T15 $($ Sec) & EN-T15 $($ Sec) & FI-T15 (Sec) \\
\hline 1 & 2.464 & 4.199 & 4.054 \\
\hline 2 & 2.155 & 3.614 & 3.724 \\
\hline 3 & 1.721 & 3.275 & 3.328 \\
\hline
\end{tabular}

TABLE V. TIME PERIODS OF PLUS-SHAPED MODELS

\begin{tabular}{|c|c|c|c|}
\hline Modes & RC-P15 (Sec) & EN-P15 (Sec) & FI-P15 (Sec) \\
\hline 1 & 2.423 & 4.460 & 4.342 \\
\hline 2 & 1.896 & 3.952 & 3.875 \\
\hline 3 & 1.891 & 3.607 & 3.628 \\
\hline
\end{tabular}

The time period of all the models considered is shown in Tables IV and V. As the time period reduces the stiffness of the building increases because time period is inversely proportional to the stiffness of the building.

\section{B. Storey Displacements}

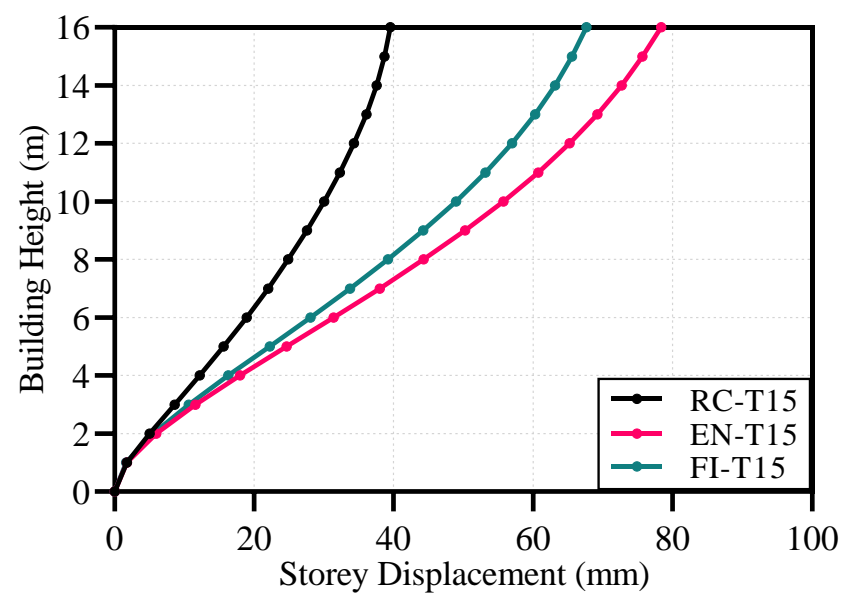

Fig. 8. Story displacement of T-shaped models in X direction 


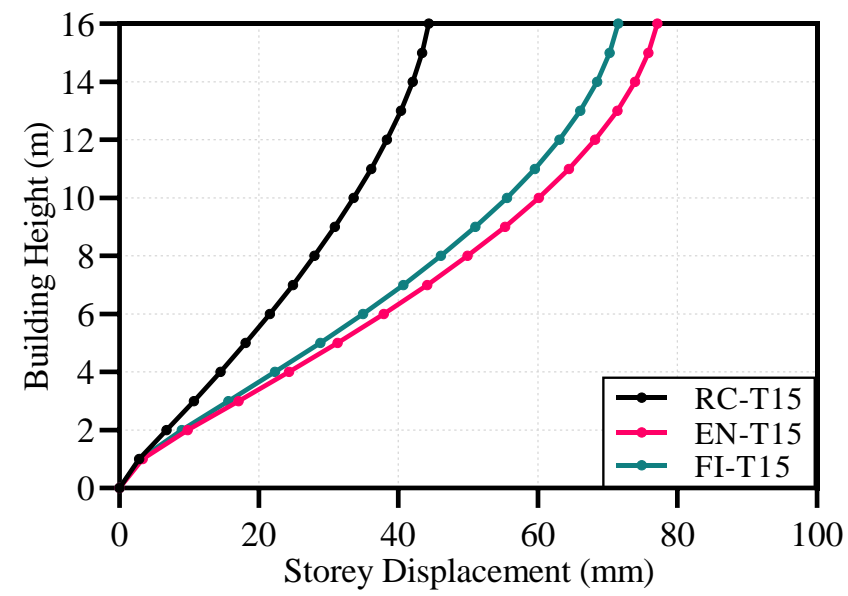

Fig. 9. Story displacement of T-shaped models in Y direction

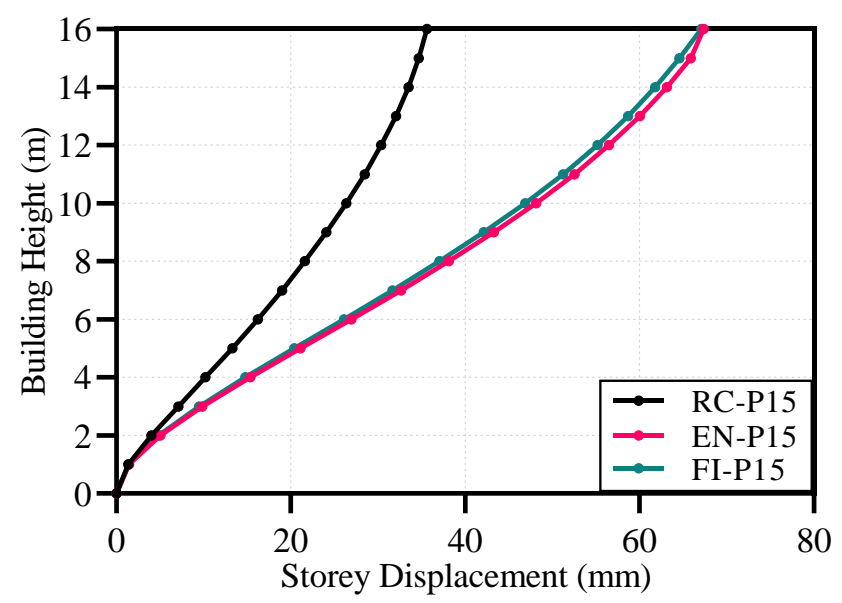

Fig. 10. Story displacement of Plus-shaped models in X direction

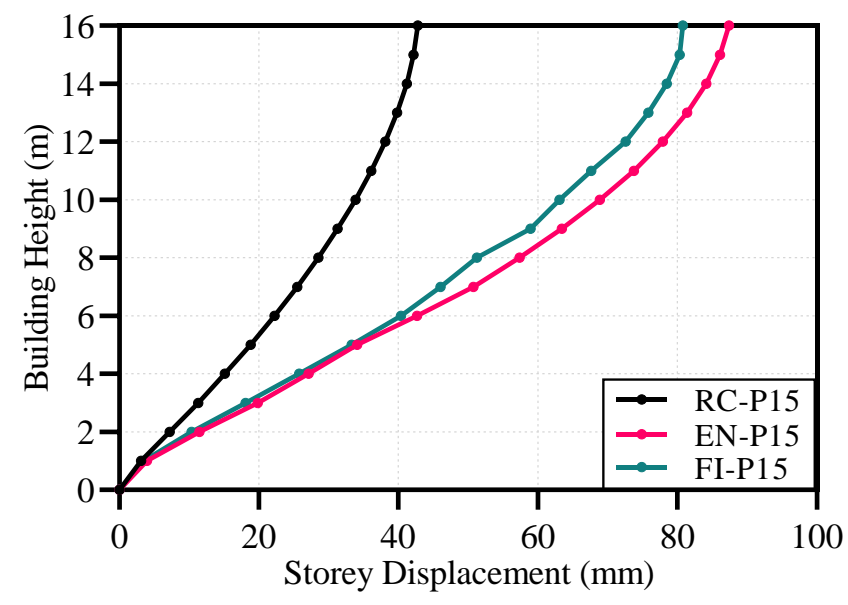

Fig. 11. Story displacement of Plus-shaped models in Y direction

Story displacements of the T-shaped models are shown in Fig. 8 and 9. It can be seen that the top storey displacement for the model EN-T15 is almost twice compared to RC-T15 and for the model FI-T15, the displacement is about $60-70 \%$ more when compared to RC-T15. Fig. 10 and 11 show that the maximum displacement for the models EN-P15 and FI-P15 is about $85-100 \%$ more when compared to the model RC-P15.
When the two composite structures are compared, it can be seen that the difference is very less.

\section{Storey Drifts}

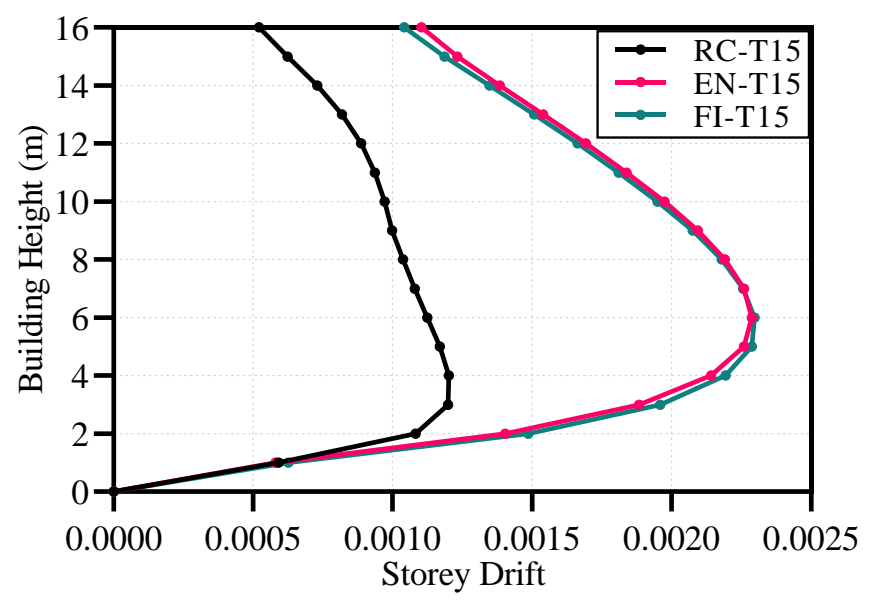

Fig. 12. Story drifts of T-shaped models in X direction

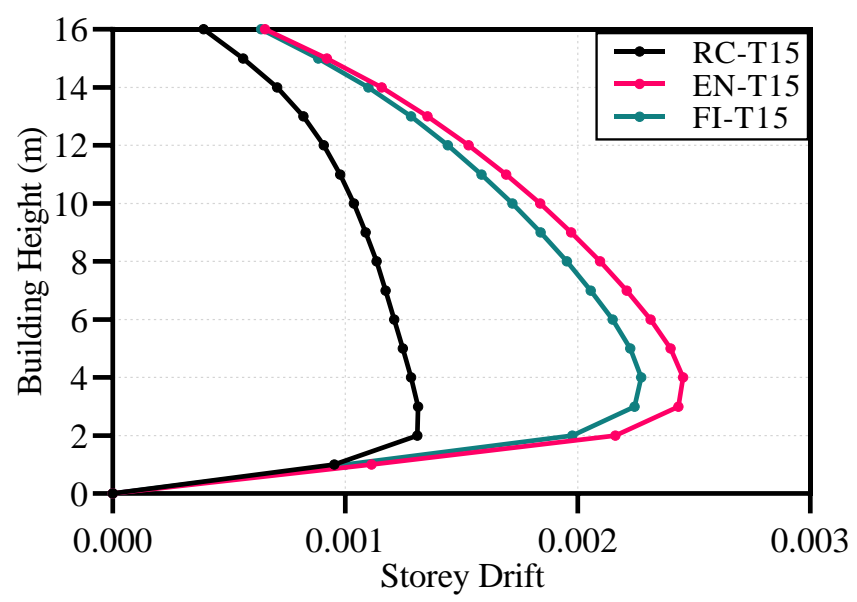

Fig. 13. Story drifts of T-shaped models in Y direction

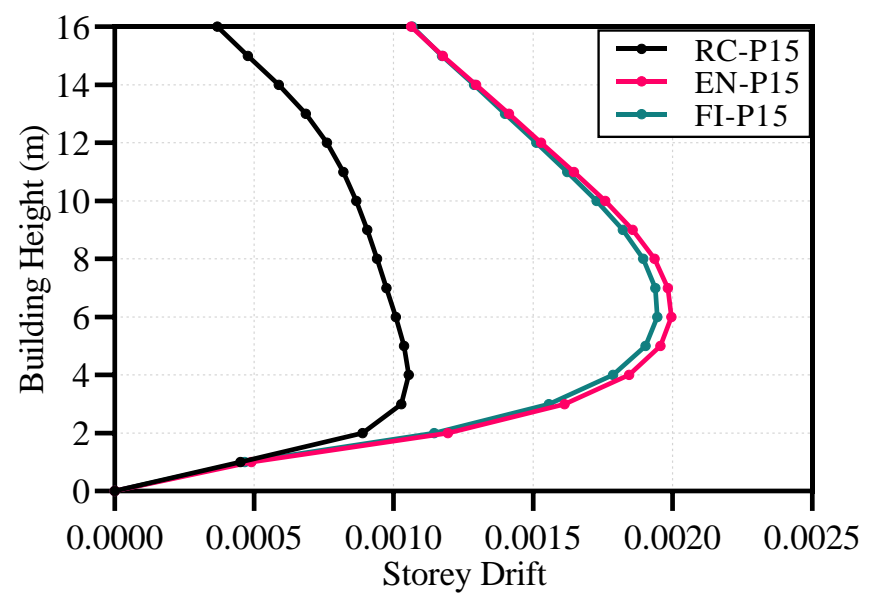

Fig. 14. Story drifts of Plus-shaped models in X direction 


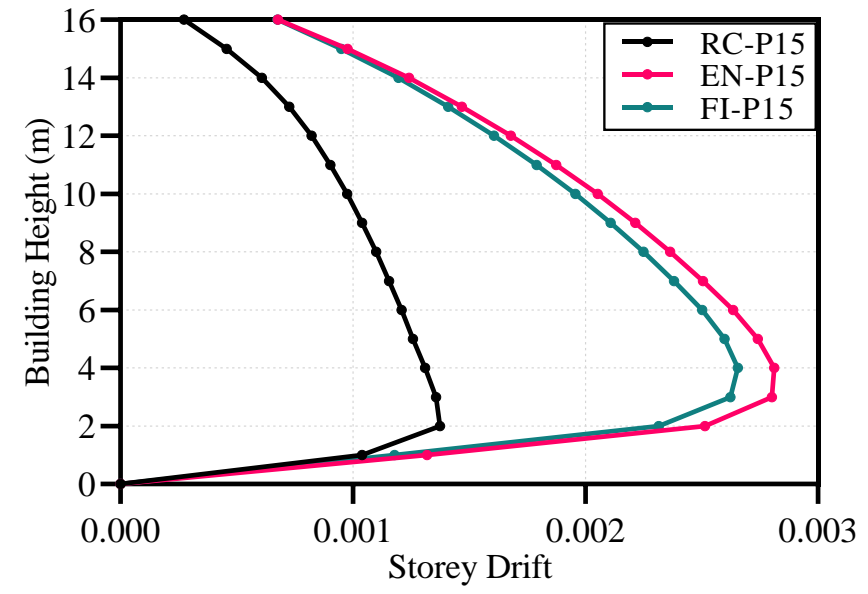

Fig. 15. Story drifts of Plus-shaped models in Y direction

The graphs in Fig. 12 and 13 shows that the storey drift for composite structure whether it is of $\mathrm{T}$ shape or Plus shape is comparatively higher than RCC structure in both transverse and longitudinal direction. The drifts in the composite models were about $80-100 \%$ more when compared to the RCC models.

\section{Storey Stiffness}

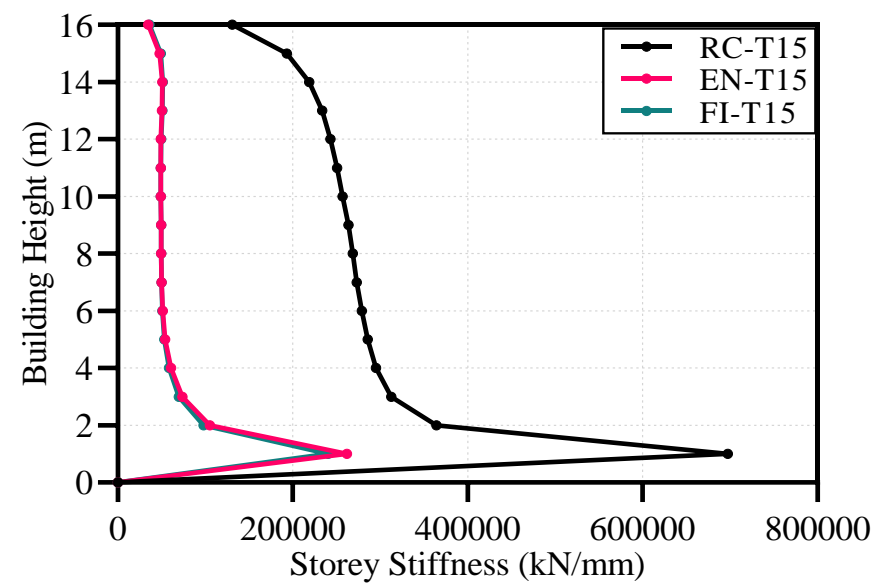

Fig. 16. Story stiffness of T-shaped models in X direction

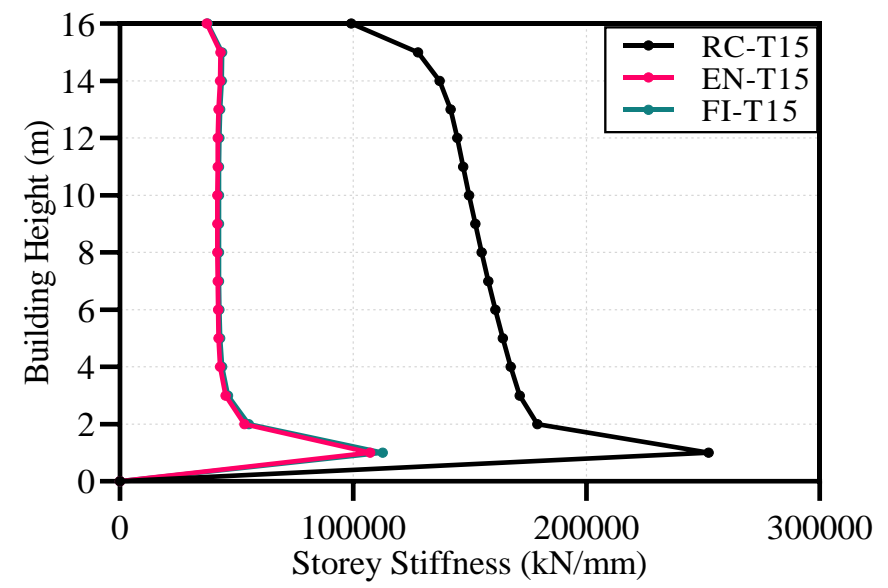

Fig. 17. Story stiffness of T-shaped models in Y direction

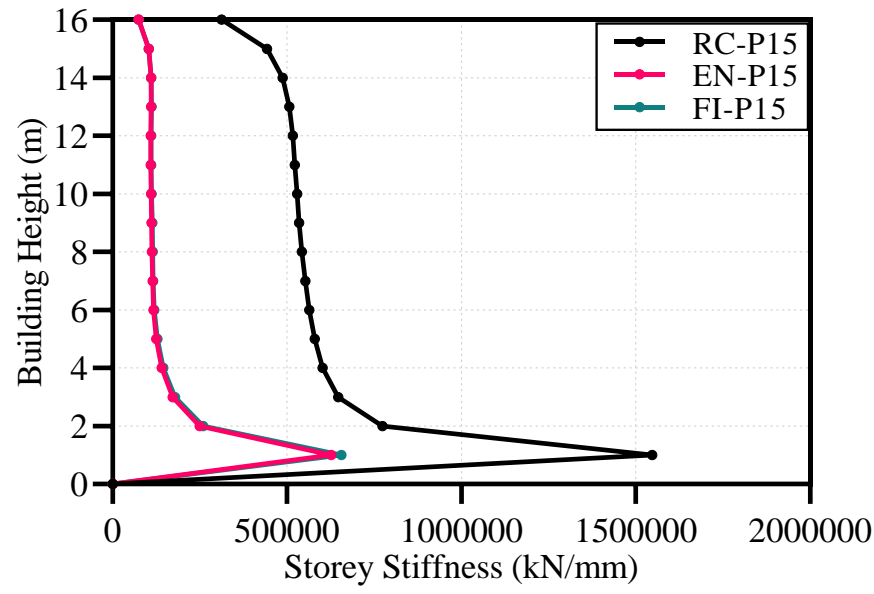

Fig. 18. Story stiffness of Plus-shaped in X direction

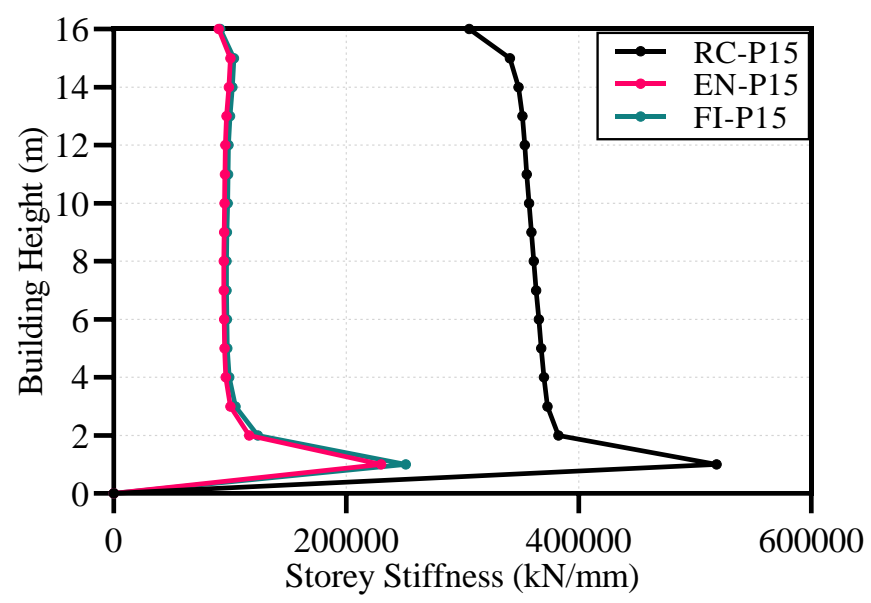

Fig. 19. Story stiffness of Plus-shaped in Y direction

Fig. 16 to 19 show the stiffness of the models. It can be seen from the figure that the stiffness of the composite buildings is less than half when compared to the stiffness of the RCC buildings. Because of inherent ductility characteristics, steel-concrete composite structures have less stiffness compared to R.C.C structures leading to better performance in the event of an earthquake.

\section{E. Base Shear}

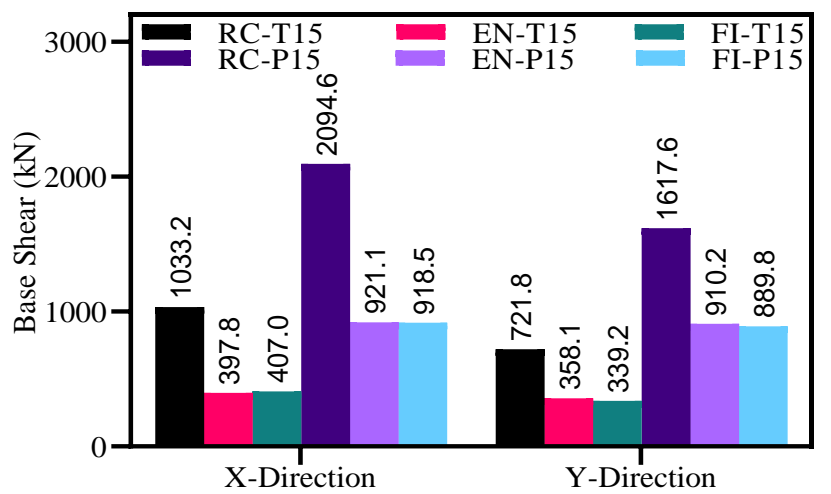

Fig. 20. Base shear of all the models 
Base shear is the horizontal reaction to the lateral forces and horizontal forces results from the storey weight. In RCC models the self-weight is more and hence resulting in the highest value of base shear. It can be seen from the Fig. 20 that the base shear for the models EN-T15 and FI-T15 in X direction is about $60 \%$ less when compared to the model RC-T15. In Y direction, the base shear for EN-T15 and FI$\mathrm{T} 15$ is about $50 \%$ less when compared to RC-T15. The base shear in the models EN-P15 and FI-P15 when compared to $\mathrm{RC}-\mathrm{P} 15$ is about $56 \%$ less $\mathrm{X}$ direction and $45 \%$ in $\mathrm{Y}$ direction.

\section{F. Overturning Moments}

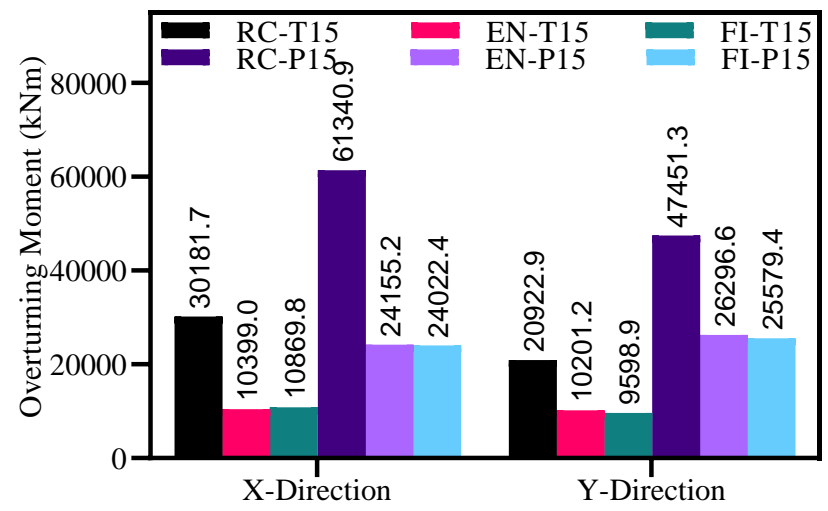

Fig. 21. Overturning Moments of all models

From Fig. 21 it can be seen that the RCC has got more overturning moment than the composite structures this is casued due to the lateral forces. The overturning moment in the models EN-T15 and FI-T15 is $66 \%$ and 54\% less when compared to RC-T15 in X and Y directions respectively. For EN-P15 and FI-P15 the overturning moment is $61 \%$ and $46 \%$ less in $\mathrm{X}$ and $\mathrm{Y}$ directions when compared to RC-P15.

\section{G. Axial Forces}

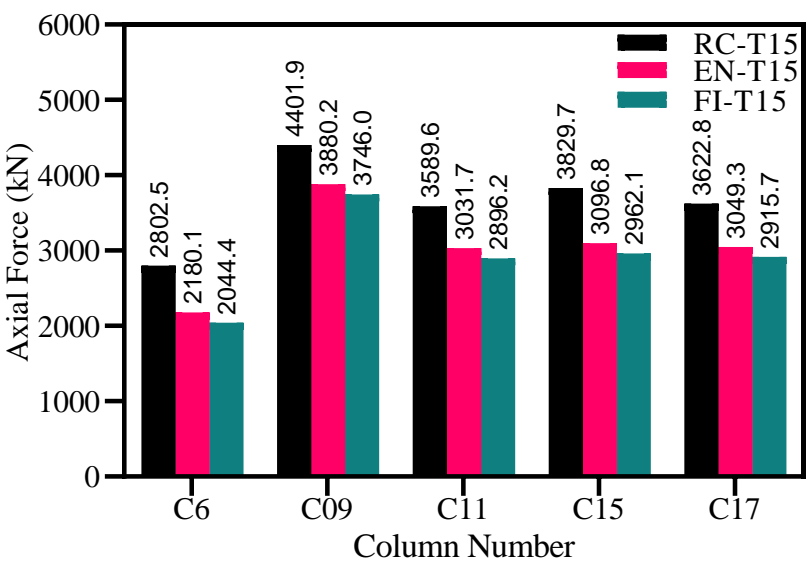

Fig. 22. Axial forces of T-shaped models

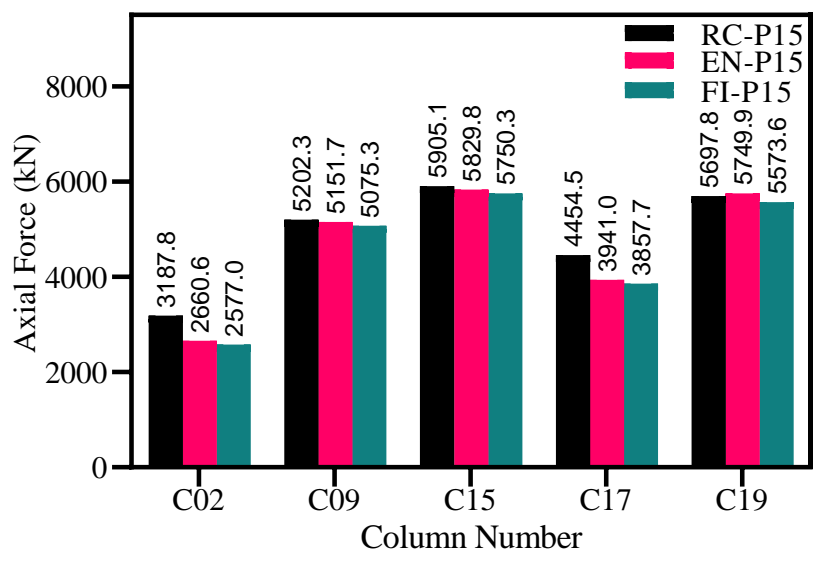

Fig. 23. Axial forces of Plus-shaped models

Fig. 22 shows the axial forces for some of the columns of T-shaped buildings. The columns C6 and C9 are corner columns, C11, C15 and C17 are edge columns (Fig. 4). Fig. 23 shows the axial forces for columns of Plus-shaped buildings. The columns $\mathrm{C} 2$ and $\mathrm{C} 9$ are corner columns, C15 and $\mathrm{C} 19$ are interior columns and $\mathrm{C} 17$ is an edge column (Fig. 6). It can be seen that the axial forces in the composite structures are less compared to RCC structure. The columns at the re-entrant corner (C9) has higher value of axial load. It can be clearly seen that internal columns experience higher forces than the external ones.

\section{CONCLUSIONS}

The following conclusions are drawn from the analysis done on the models.

- The displacements in the composite structures are more when compared to RCC structures but within the limit of the IS codal provisions.

- The storey stiffness in composite structures in nearly half compared to RCC, thereby increasing the ductility of the structure.

- The base shear and base moments are also very less compared to RCC structure. This could be due to the fact that the dead weight of RCC is more compared to composite structure.

- When the two composite structures were compared, it was found that there is no significant difference in the response parameters of the structure with concrete filled steel tubular columns and with concrete encased I section columns.

\section{REFERENCES}

[1] Vamshi Krishna and Surendhar, S, V., "Comparison of Seismic Analysis of a Residential Composite and RCC Structure," International Journal of Innovative Technology and Exploring Engineering, 2019, 8(6), 113-119.

[2] Sachin, S. and Shyam Prasad, HR., "Study of Seismic Behavior on Multi-Storied buildings with Composite Columns." International Journal for Research in Applied Science and Engineering Technology, 2018, 6(4), 4779-4785.

[3] Sohail Shaikh and Shilpa Kewate., "Behaviour of Concrete Encased Columns in Irregular Buildings under Seismic Conditions" International Journal of Engineering Science Invention, 2018 , 7(6), 9296. 
[4] Vishwanatha. S, N., "Seismic Analysis of Multistoryed RCC and Composite Building Subjected to Vertical Irregularity" International Research Journal of Engineering and Technology, 2018, 5(5), 32683633.

[5] Muhammed Sabith K., "Seismic Analysis of Irregular Composite Structures with Shear Connectors using Etabs" International Journal of Scientific Research and Engineering Trends, 2017, 3(3), 1-7.

[6] Rajendra Bhoir, R. Vinay Kamble., "Analysis and Design of Composite Structure \& Its Comparison with RCC Structure" International Journal for Research in Applied Science and Engineering Technology, 2017, 5(10), 88-94.

[7] Vardharajan, S. Sehgal, V. K and Babita Saini., "Review of different Structural irregularities in Building" Journal of Structural Engineering, 2013, 39(05), 538-563.

[8] Ilyas A, Azeem MA and Mohiuddin H., "Seismic Response of Reinforced Concrete Buildings under Mainshock-Aftershock Earthquake Sequence" International Journal of Civil Engineering and Technology, 2018, 9(4), 647-59.

[9] Ali MM and Azeem MA., "Linear Dynamic Response Spectrum Analysis on different Geometric Plans of Frame Tube Structures" International Journal of Engineering Research in Mechanical and Civil Engineering, 2019, 4(1), 1-9, DOI: 01.1617/vol6/iss1/pid04697

[10] BIS (Bureau of Indian Standard). (2000). "Plain and Reinforced Concrete Code of Practice" IS 456:2000, New Delhi.

[11] BIS (Bureau of Indian Standards). (2002). "Criteria for Earthquake Resistant Design of Structures, Part 1 - General Provisions and Buildings." IS 1893:2002 (Part - 1), New Delhi.

[12] AISC (American Institute of Steel Construction). (2015). "Composite Column Design Manual” AISC 360-10, United States. 